\section{Actores sociales en la prevención del VIH/SIDA: oposiciones e intereses en la política educativa en México, 1994-2000}

\author{
Social actors in HIV/AIDS prevention: opposition \\ and interests in educational policy in Mexico, \\ 1994-2000
}

\author{
${ }^{1}$ Maestría en Medicina Social, \\ Universidad Autónoma Metro- \\ politana, México DF, México. \\ 2 Departamento de Atención a \\ la Salud, Universidad Autóno- \\ ma Metropolitana, México DF, \\ México. \\ Correspondencia \\ J. A. Granados-Cosme \\ Maestría en Medicina Social, \\ Universidad Autónoma Metro- \\ politana. \\ Calzada del Hueso 1100, Col. \\ Villa Quietud 04960, Coyoacán, \\ México DF: \\ jcosme@correo.xoc.uam.mx
}

\section{Abstract}

Studies and recommendations by health agencies have emphasized the importance of education in HIV-AIDS prevention. Mexico has included topics on sexuality and HIV-AIDS in school programs, triggering resistance by some social actors. The current study seeks to clarify the various positions and interests and their influence on the textbook content. A literature search was conducted on the period during which the last educational reform was implemented in Mexico. The discourse analysis focused on the ethnography of communication, which identified: the various actors' positions, arguments, actions, economic and political power, and relations to others. The results show that those who oppose the inclusion of these themes in the school curriculum base their position on tradition, contrary to modernization and secularization of social life, and that their positions range from refusal to raising conditions. Networks have been formed that provide such groups with significant economic and political power. Government has given in to some demands by partially modifying the textbook contents. The current analysis proposes to reflect on the potential repercussions of such actions on the control of the epidemic.

HIV; Acquired Immunodeficiency Syndrome; Health Education; Public Policies
José Arturo Granados-Cosme 1

Kittipong Nasaiya ${ }^{1}$

Alberto Torres Brambila 2

\section{Introducción}

Desde los inicios de la pandemia delVIH/SIDA se postula que la mejor estrategia es la prevención, debido a la capacidad mutagénica del virus que hace improbable encontrar medidas curativas a corto plazo. La vía de transmisión más frecuente es la sexual, por ello, las medidas preventivas buscan disminuir este riesgo; al respecto se plantea que entornos intolerantes hacia la diversidad sexual son poco propicios para que los individuos adopten prácticas preventivas 1 .

Organismos sanitarios internacionales recomiendan a gobiernos nacionales instrumentar políticas preventivas basadas en la educación y promoción de la salud que incluyan: conocimiento de medidas preventivas, vías de transmisión, situaciones que facilitan la infección (explotación sexual, abuso, violencia doméstica, violencia sexual, conceptos erróneos y mitos sobre sexualidad, matrimonios prematuros), información para el uso del condón, redes sociales, eliminación del estigma, vergüenza y discriminación (reconocimiento de la diversidad sexual, respeto a derechos humanos y aceptación de seropositivos), defensa y protección del derecho a la salud, la atención médica, el trabajo y los derechos sexuales 2 . Sin embargo, en la educación básica en México se cumple con la mitad de las recomendaciones y las incluidas tienen carencias 3 . 
Lo anterior resalta el papel de la educación en salud que se recibe en las escuelas y que generalmente se entiende como un proceso de información individual que contribuye a generar cambios conductuales benéficos. Esto supone que la disponibilidad de información permite que los individuos adopten conductas saludables. Otros autores enfatizan que además de proporcionar información a los niños se les debe adiestrar en las habilidades necesarias para que ejerzan la conducta deseada. Ambas posturas se centran en la conducta individual y los análisis que profundizan en los procesos políticos, económicos y sociales son más bien limitados 4 .

Debe agregarse que los adolescentes demandan información, en Corea el 94,4\% de los jóvenes manifestaron la necesidad de recibir educación sobre VIH y consideraron la escuela uno de los medios más importantes 5 . Para garantizar el derecho a recibir información, en Chile se recomendó incluir contenidos sobre sexualidad y prevención del SIDA en el currículum escolar 6 . En Francia y el Congo el tema del VIH/SIDA forma parte de los cursos de biología en la educación básica, se pretende no sólo dar información científica, sino convencer a los estudiantes para que adopten medidas preventivas en su conducta 7 . Las acciones educativas afectan positivamente el control de la epidemia, promover el condón se vincula con prácticas sexuales de bajo riesgo; la educación sobre SIDA y sexualidad en escuelas norteamericanas no tiene efectos significativos para la abstinencia, pero sí para el sexo protegido, estos resultados sugieren que la información no promueve las relaciones sexuales, sino la protección en éstas, reduciendo la transmisión y disminuyendo los costos sociales 8 .

A partir de los sesenta, la participación social se convirtió en una preocupación para la sociología; el interés estuvo motivado por los movimientos juveniles y contraculturales de entonces 9,10. La jerga especializada incluyó el término de actores sociales refiriéndose a conglomerados de individuos que se manifestaban buscando espacios de participación, denunciando, demandando o interfiriendo acciones públicas, particularmente las gubernamentales. El funcionalismo argumentó que la acción social se explica por las creencias que provocan conductas colectivas producto de tensiones que afectan al sistema social. Esta perspectiva supone que el fin último es restablecer los equilibrios y explica el conflicto como una tendencia a conservar el orden en el que los actores son sujetos pasivos, sus conductas, naturaleza social y relaciones con los otros están determinadas por ese orden. El marxismo enfatizó las condiciones que facilitan el surgimiento de los movimientos y postuló que éstos se explican mediante el análisis de las relaciones de clase y el paso de la acción política al cambio social; en esta perspectiva el sistema es producto de la acción e interacción social 9 .

El análisis de los actores sociales distingue tipos de conductas colectivas: crisis organizativas por conflictos internos (provocan demandas), tensiones institucionales donde los actores buscan incidir en la toma de decisiones que pueden afectarlos y propuestas modernizadoras para el cambio por inconformidad contra el orden establecido y oposición a la dominación. También debe observarse el sistema de relaciones, conocer la posición de los actores en dicho sistema, su poder económico y político, ya que esto facilita u obstaculiza su interlocución con instancias estatales 11 . Dada la especificidad y temporalidad de sus intereses, los actores se encuentran fragmentados, son temporales y muestran ciclos de movilización y latencia, conformando estructuras reticulares con diversos liderazgos 12; los componentes de la acción colectiva son sus valores, normas, motivaciones y recursos 13 .

Como práctica social, la médica tiene por contenidos saberes y actividades organizados coherentemente para responder a problemas sanitarios. La vigencia y predominio de la medicina científica alcanzó su institucionalización en política pública en cuya definición intervienen agentes sociales portadores de intereses que expresan valores éticos y propósitos contrapuestos.

El VIH/SIDA intensificó el interés por la participación social, se reconoció que los movimientos sociales son importantes catalizadores para el cambio, pues impactan en las políticas públicas. Además, tienen capacidad para movilizar recursos comunitarios, particularmente en zonas metropolitanas 14 . No obstante, el consenso de proveer información científica que permita a los alumnos prevenirse del VIH/SIDA; la educación sobre sexualidad y uso del condón son medidas que generan inconformidades y moviliza a ciertos grupos. Históricamente, el Vaticano condena la anticoncepción y el aborto, se opone radicalmente al uso del condón en la prevención delVIH/SIDA y el embarazo 15; como la Iglesia Católica, otros grupos buscan influir en la definición de medidas públicas para controlar la enfermedad; adquiere relevancia entonces conocer los argumentos y la influencia de los grupos opositores en la política educativa de prevención del VIH/SIDA. Para responder estas interrogantes se realizó una investigación que permitiera identificar a quienes se pronuncian sobre estos temas. 


\section{Antecedentes históricos}

En México, la educación es un derecho social y es impartida principalmente por el Estado, tiene como rasgo fundamental el laicismo, sus contenidos son regulados mediante libros de texto gratuitos para todos los alumnos de escuelas públicas; los programas se desarrollan en grados anuales, la educación primaria comprende seis y se imparte a niños entre 6 y 12 años de edad, mientras que la secundaria comprende tres y se imparte a niños de 13 a 15 años.

Las controversias sobre los contenidos relacionados con la sexualidad en la educación pública en México ocurren posteriormente a la Revolución Mexicana (1910). Un elemento de la educación estatal que genera debates públicos y toma de posiciones es su carácter laico. En el gobierno de Elías Calles (1924-1928) se consolidó la participación estatal en materia educativa, marginando el anterior predominio de la Iglesia, esto generó la oposición de quienes argumentaban que se coartaba la "libertad irrestricta" de los padres de familia en la enseñanza de sus hijos.

Posteriormente, se agregó otro elemento de discusión: la introducción del carácter socialista durante la gestión de Narciso Bassols en la Secretaría de Educación Pública (SEP) (1932-1934) quien propuso implementar contenidos sobre sexualidad en la educación primaria, dicha propuesta retomaba experiencias de otros países que habían mostrado buenos resultados y su intención era aplicar educación sexual desde el tercer grado de primaria. Los opositores consideraban que el Estado se estaba "disputando el alma de los niños", que se generaría una "confusión de la inocencia" y que representaba "la pérdida del pudor y el temor de Dios" 16 (p. 2); entre otros lemas pregonaban: "ni sodomitas ni prostitutas, abajo la educación sexual" o "ni un paso más al abismo”. Uno de los grupos más destacados en esta posición es la Unión Nacional de Padres de Familia (UNPF) que se opone permanentemente a la educación laica y a los contenidos sobre sexualidad. La pugna concluyó eliminando la iniciativa estatal y con la renuncia de Bassols 17 .

Durante el gobierno de López Mateos (19581964) se propuso la edición y distribución gratuita de libros para la educación primaria (1962) 16 y resurgió el debate al que se agregó la gratuidad. En la discusión participaron la Iglesia Católica, grupos empresariales y el sector educativo privado. Cuestionaban el papel del Estado en la enseñanza, argumentando que su monopolio restringía la libertad de los padres para elegir el tipo de educación de sus hijos. Se discutía la gratuidad porque los opositores consideraban que con los libros gratuitos el Estado se abrogaba el derecho de definir los contenidos; aunque la UNPF decía no rechazar la gratuidad, sí se oponía a la "imposición" de dichos libros como textos obligatorios y universales 18 .

En el gobierno de Echeverría (1970-1976) se reformaron los planes y programas de estudio en cuyo proceso se elaboraron nuevos libros 19. En 1972 se integraron contenidos sobre sexualidad 16 que generaron nuevas discusiones sobre los atributos laico, gratuito y socialista de la educación pública; la UNPF se pronunció contra los libros porque según ellos, sus contenidos promovían la masturbación, pues los textos enunciaban que era "enteramente normal en la adolescencia" y que "no provoca trastornos físicos ni mentales” 17 (p. 51); decían que los libros de ciencias naturales eran "pornográficos" 19. La reacción de los opositores incluyó quemas de ejemplares de libros en plazas públicas por contener gráficos que ilustraban diferencias anatómicas entre hombres y mujeres, así como los aparatos reproductivos 17,20 .

En la segunda edición del libro de ciencias naturales para sexto grado de primaria (19751976), la jerarquía católica presionó a las autoridades para modificar ilustraciones en que aparecían desnudos un niño y una niña, la exigencia de cubrir los genitales fue cumplida por el gobierno haciendo aparecer a los niños en "traje de baño" 16,17. Algunos obispos manifestaron aceptar la educación sexual, pero advertían que debía estar "encuadrada en un conjunto de valores morales” 16 (p. 2). Durante los ochenta, grupos laicos y religiosos dijeron asumir lo que llamaron "su responsabilidad" y organizaron cursos de orientación sexual en escuelas privadas, en ellos promovían la virginidad y la abstinencia 20 .

El debate sobre los contenidos de sexualidad en la educación pública se vio sustancialmente modificado con los cambios en la relación Estado-Iglesia del gobierno de Salinas (1988-1994). En 1992 se aprobó la reforma al artículo constitucional que regulaba la injerencia del clero en política pública. Según sus promotores, la medida fortalecía la libertad religiosa; pero en términos prácticos amplió el margen de influencia clerical, de lo cual quien más se benefició fue la Iglesia Católica. Aunque con frecuencia esta iglesia intentó recuperar el poder público perdido en la secularización de la vida social promovida por Juárez (1858-1861), su intervención en asuntos públicos era ilegal y sus pronunciamientos estaban limitados. Con la reforma salinista la Iglesia Católica tiene mayor acceso a medios de comunicación, donde difunde sus posiciones respecto a cualquier asunto público. En este marco es donde surge la política estatal de "modernización educativa". 


\section{Objetivo}

Identificar a los actores sociales tradicionalistas que buscan intervenir en la definición de contenidos sobre sexualidad y VIH/SIDA en la educación laica en México.

\section{Material y método}

Se analiza la composición del discurso mediante la identificación de categorías discursivas en las que conceptos, temas y lemas revelan intereses. El discurso es un recurso para la reproducción y transformación cultural, una práctica en la que se recrean significados que constituyen la cultura. En el discurso se establecen relaciones de poder que imponen significados que conforman una ideología dominante. El lenguaje es productor de acciones, de prácticas que retroalimentan y transforman las representaciones sociales. El lenguaje y las acciones producidas por éste se inscriben en formas de organización social, la delimitación más importante es la institución, en ella el discurso es instrumento de comunicación, pero también de poder, ya que mediante éste se norma la conducta 21 .

En la etnografía de la comunicación la unidad de análisis es el evento del habla, compuesto por formas de habla (diálogo o texto) y los hechos externos (formas extralingüísticas). La situación comunicativa se caracteriza relacionando el evento de habla en particular con su contexto (institución en que se realiza, instituciones con que se relacionan y acciones que produce) 22. En este caso, la situación se constituye a partir de la inclusión de nuevos contenidos sobre sexualidad y prevención delVIH/SIDA en los libros de texto, lo que permite caracterizar la movilización de actores sociales y su toma de posición. Posteriormente, se distingue la significación que tienen sobre estos temas a partir de los valores y principios que sustentan sus posiciones; las acciones se ponderan mediante la influencia que ejercen en la política pública y el cambio de las acciones gubernamentales.

Entre 1994 y 2000 tuvo lugar la última reforma con que se modificaron los libros; este periodo delimitó la investigación hemerográfica. Los libros que contenían información nueva sobre sexualidad y VIH/SIDA fueron los de ciencias naturales para los dos últimos grados de educación primaria, el de biología y los de formación cívica y ética de educación secundaria. Éstos motivaron reacciones de los opositores por los temas que tratan en las lecciones que se muestran en la Tabla 1.

Para obtener el discurso de los actores opositores se seleccionaron diarios de circulación nacional que contaran con sistema de búsqueda electrónica para dicho periodo. Se incluyeron periódicos nacionales, pues la reforma educativa fue una política federal aplicable al territorio nacional, por ello se excluyeron los diarios locales. La búsqueda de notas periodísticas se realizó a través de expresiones boleanas que combinaron palabras clave: sexualidad, VIH/SIDA, libros de texto y educación; las notas se seleccionaron al corroborar que efectivamente se relacionaran con el debate público. Posteriormente se procedió a recuperar la fuente impresa, con ellas se realizó un análisis del discurso en que se identificó: emisor, tema, posición del emisor (acuerdo o desacuerdo con los nuevos contenidos), argumentos que sustentan su posición, demandas que plantean y acciones generadas (cambios en los contenidos previstos). Para documentar el poder económico y político de los actores se analizó la información que dichas organizaciones ofrecen en sus páginas Web, identificándose sus filiaciones políticas, recursos económicos y nexos.

\section{Resultados}

La emisión de notas muestra una secuencia cíclica en la movilización de los actores opositores; los pronunciamientos son más frecuentes al inicio de los ciclos escolares (septiembre) y en los años que se presentaron los nuevos libros (1998 y 1999) (Tabla 2). Lo anterior, nos permite afirmar que los opositores reaccionan movilizándose coyunturalmente ante innovaciones de la política pública; nos habla también de la temporalidad de sus movilizaciones ${ }^{12}$. Los principales actores sociales opositores se describen a continuación.

\section{Unión Nacional de Padres de Familia}

Se fundó en 1917, dice responder al llamado del Papa León XIII para solucionar la "cuestión social" de la época. Busca mejorar las condiciones de vida de las familias, "engrandecer los valores familiares", mejores medios para una educación "adecuada", defiende los derechos y deberes de los padres en un entorno "moralmente sano" 23; centra su atención en el carácter laico de la educación pública e insiste en modificar el artículo tercero constitucional que lo garantiza. Sus estrategias buscan influir en la edición de los libros de texto gratuitos, de los que mencionan que son "causa" de que los jóvenes no lleguen "vírgenes" al matrimonio. Su argumento discursivo es que la política educativa estatal viola los derechos de los padres quienes, según la organización, deben ser los primeros y principales educadores. Sus 
Contenidos sobre sexualidad y VIH/SIDA en los libros de texto en México.

\begin{tabular}{|c|c|c|}
\hline Libro de texto & Grado & Contenido por tema \\
\hline Ciencias naturales & Quinto grado de primaria & $\begin{array}{l}\text { - Las mujeres son distintas a los hombres. } \\
\text { - Los hombres son distintos a las mujeres. } \\
\text { - Especie e individuos, semejanzas y diferencias. } \\
\text { - Las oportunidades para mujeres y hombres deben ser las mismas. } \\
\text { - La diversidad humana. }\end{array}$ \\
\hline Ciencias naturales & Sexto grado de primaria & $\begin{array}{l}\text { - Los cambios del cuerpo en la adolescencia. } \\
\text { - El camino hacia la edad adulta. } \\
\text { - La reproducción humana. } \\
\text { - La cultura de la prevención. }\end{array}$ \\
\hline Biología & Primer grado de secundaria & $\begin{array}{l}\text { - Sistema reproductor femenino y masculino. } \\
\text { - Fecundación y embarazo. } \\
\text { - Métodos anticonceptivos. } \\
\text { - Enfermedades de transmisión sexual. }\end{array}$ \\
\hline Formación cívica y ética 1 & Primer grado de secundaria & $\begin{array}{l}\text { - Un ser libre capaz de decidir. } \\
\text { - Un ser sexuado. } \\
\text { - Sexualidad. }\end{array}$ \\
\hline Formación cívica y ética 2 & Segundo grado de secundaria & - Amistad, compañerismo y otras relaciones afectivas. \\
\hline Formación cívica y ética 3 & Tercer grado de secundaria & $\begin{array}{l}\text { - Sexualidad y género. } \\
\text { - Implicaciones de la sexualidad en las relaciones humanas. } \\
\text { - Aspectos emocionales de la sexualidad. } \\
\text { - El respeto a las otras personas. } \\
\text { - Madurez emocional y responsabilidad en las relaciones sexuales. } \\
\text { - Métodos anticonceptivos. } \\
\text { - Virus de inmunodeficiencia humana }(\mathrm{VIH}) \text { y el SIDA. }\end{array}$ \\
\hline
\end{tabular}

Fuente: elaboración propia en base a la revisión de los libros de texto gratuitos para la educación primaria y secundaria, Secretaría de Educación Pública (México).

miembros se definen a sí mismos "inspectores" de la moral pública. Entre sus medios de difusión editan una revista mensual, libros y folletos; organizan campañas informativas, conferencias y cursos donde difunden críticas a la anticoncepción, la homosexualidad, el aborto y la masturbación. En cuanto a su poder económico tienen vínculos con la Confederación Nacional de Escuelas Particulares y con la Confederación Patronal de la República Mexicana (COPARMEX) (Eloy Salazar, por ejemplo, es asesor de la COPARMEX y de la UNPF); se vinculan con la Asociación Católica de la Juventud Mexicana, pertenece a la Unión Iberoamericana de Padres de Familia (UNIAPA), donde cuenta con cargos directivos. La organización realiza actividades conjuntas con la Iglesia Católica, varios de sus miembros son representantes del Partido Acción Nacional (PAN) a nivel municipal, estatal y nacional 17,24. Sus acciones se dirigen contra innovaciones de la SEP y programas de anticoncepción y prevención delVIH/ SIDA de la Secretaría de Salud (SS) 25.
Tabla 2

Distribución y número de notas periodísticas por periodo.

\begin{tabular}{llc}
\hline Año & Periodo & Número \\
\hline 1994 & Septiembre & 1 \\
1995 & Diciembre & 1 \\
1998 & Enero a abril & 5 \\
1998 & Julio a noviembre & 25 \\
1998 & Octubre a diciembre & 6 \\
1999 & Enero & 2 \\
1999 & Febrero a noviembre & 3 \\
1999 & Abril & 2 \\
1999 & Mayo a junio & 2 \\
1999 & Julio a noviembre & 7 \\
2000 & Enero a abril & 4 \\
2000 & Junio a agosto & 4 \\
2000 & Diciembre & 1 \\
\hline
\end{tabular}

Fuente: elaboración propia. 
Guillermo Bustamante fue presidente de la UNPF (1986-1992), y del 2000 en adelante fue presidente de la UNIAPA. Sus declaraciones revelan una radicalización de su organización, ya que su predecesor (Ricardo Esponda) había propuesto que los nuevos contenidos de los libros de texto tenían que ser "optativos”. Bustamante fue más radical, manifestó su rechazo total y demandó retirar los libros; se opone a incluir temas sobre sexualidad considerando que la instrucción sobre ésta es un derecho exclusivo de los padres, ha dicho que promueven la homosexualidad, mostrando que la organización rechaza esta orientación sexual. El dirigente afirma que ha trabajado de manera conjunta con la SEP.

Ricardo Esponda fue nuevamente presidente de la organización (1997-2001). Es empresario afiliado a la COPARMEX 17, declaró no oponerse a los libros ni a la educación sexual, menciona tener "acuerdos personales" con la SEP y que sus gestiones han sido un "triunfo" que permitió la cooperación con la secretaría, ante la cual ha solicitado una mayor participación de su organización y de los padres de familia en la educación pública.

La posición de la organización se opone a promover el condón, a cualquier referencia sobre los órganos reproductivos, expresa juicios de valor sobre trabajadores sexuales, homosexuales y madres solteras, al considerar que las relaciones sexuales deben realizarse únicamente en el ámbito familiar.

\section{Comité Nacional PROVIDA}

Esta asociación civil surge en 1978, según ella misma, como reacción a una iniciativa de ley del Partido Comunista para legalizar el aborto en México. Dice tener cobertura nacional, vínculos internacionales y delegaciones en todo el país, su objetivo es fomentar la "verdadera cultura de la vida" basada en "virtudes y valores humanos", y dar a conocer el "verdadero" significado de la sexualidad para erradicar consecuencias como los embarazos en adolescentes, el SIDA y el aborto 26 . Las únicas medidas que aceptan para controlar la natalidad y prevenirse delVIH/ SIDAson elmétodo Billing, la abstinencia sexualy la fidelidad mutua, oponiéndose al uso del condón 17.

PROVIDA cuestiona la efectividad del condón y asegura que las campañas que lo promueven no darán resultados favorables y el SIDA seguirá progresando 26, citan algunos reportes de baja eficacia del condón y cuestionan: “¿cuál es la tasa de fallos? [...] ¿quién responde por ellos?”, asegura que "su promoción es una publicidad engañosa basada en dogmas de fe [...] los estudiantes no lo usan, son inmaduros, impulsivos, arriesgados en la satisfacción inmediata [...] el manejo de los condones en adolescentes es un desastre [...] los usuarios del preservativo tienen una tasa de infección que no es estadísticamente significativa comparado con los que no lo usan [...] El impulso del preservativo no representa ninguna solución, antes al revés, puede significar multiplicar el problema..." 26. Según esta organización, en lugar de recomendar el condón, el Estado debe promover "los valores", la abstinencia y la fidelidad mutua que son métodos “100\% seguros" y más fáciles de promover; postula que el ejercicio de la sexualidad debe orientarse a la reproducción y por tanto, basarse en la heterosexualidad y en los valores "familiares" 27; revelando juicios negativos sobre la homosexualidad y el VIH/SIDA, ya que dicen "quien enferma de SIDA, está condenado a una muerte más próxima de lo esperado", "La práctica homosexual es una conducta relacionada con la violencia traumática [...] favorece los desgarres y existe un elevado número de relaciones con personas diversas" 26.

Dirigen sus acciones hacia la SS por sus campañas de promoción del uso del condón. Desde los años ochenta se coordinan con la UNPF, FUNDICE, Enlace, la Iglesia Católica y empresas de gran poder económico como Pedro Domeq y Bimbo para organizar discusiones públicas contra el condón. Dicen tener cooperación con el PAN y participar conjuntamente en manifestaciones públicas contra propuestas legislativas para permitir el aborto. Se oponen a actividades de MEXFAM (Fundación Mexicana para la Planificación Familiar), del Consejo Nacional de Población (CONAPO) y de Católicas por el Derecho a Decidir. MEXFAM ofrece información y atención médica con una perspectiva de respeto a los derechos sexuales y reproductivos, difunde la práctica de la regulación voluntaria de la fecundidad 28; CONAPO es una instancia gubernamental que coadyuva en acciones estatales para controlar la natalidad; Católicas por el Derecho a Decidir es un grupo de mujeres que se oponen a prácticas discriminatorias de su Iglesia hacia las mujeres 17; PROVIDA frecuentemente obstaculiza las actividades de estas organizaciones.

Algunos representantes militan simultáneamente en el PAN, como su fundador Jaime Aviña; Alfonso Bravo (expresidente de PROVIDA) fue secretario de la Comisión de Población de la Cámara de Diputados, presidida por el PAN en 1994 17, PROVIDA ha declarado su coincidencia con los principios doctrinarios de la organización y el PAN: "podemos hablar en el mismo idioma y términos” 29 (p. 17). PROVIDA apoyó la candidatura panista de Vicente Fox en la elección presidencial del 2000, mencionan que mantienen 
vínculos con grupos internacionales similares como Human Life International, National Right to Life, Catholics United for Life, Aliento de Vida y Aleta México 26.

El personaje más notable de PROVIDA es Jorge Serrano, segundo presidente de la organización (1987-2001), su hermano es “asesor espiritual" del Movimiento Testimonio y Esperanza, un grupo radicalmente católico ${ }^{17}$. Sus declaraciones contra la SS se caracterizan por su vehemencia y fundamentalismo, su posición rechaza la homosexualidad considerándola una aberración, indica que la finalidad del acto sexual debe ser la reproducción; oponiéndose a la masturbación, al uso del condón y al aborto, con ello promueve los "valores familiares".

\section{Jerarquía de la Iglesia Católica}

Esta Iglesia fue la más beneficiada por las reformas a la relación Estado-Iglesia y encontró en medios masivos de comunicación una interlocución sin precedentes. Se menciona que el Estado mismo le "entregó" a la Iglesia la vida cotidiana, todo lo relativo a la sexualidad y la familia 30 . El discurso católico sobre sexualidad indica a la heterosexualidad como norma y a la reproducción como fin; podemos deducir que cuando postula los "valores familiares" se refiere al arreglo familiar tradicional (monogámico, heterosexual y sancionado por la ceremonia religiosa), igualmente penaliza la homosexualidad y la masturbación. Su radicalismo se manifiesta cuando afirman que existe únicamente una concepción "verdadera" de la sexualidad y un conjunto de valores "universales" 17; conductas no heterosexuales, fuera del matrimonio y sin fines reproductivos son catalogadas pecaminosas 31 .

La Iglesia Católica se opone reiteradamente a incluir información científica sobre sexualidad y prevención del VIH/SIDA en la educación. Sus expresiones varían, algunos representantes manifiestan un total rechazo mientras que otros matizan su discurso mencionando no oponerse "directamente" a la educación sexual, sino al sistema educativo por su "laicismo", aceptan la educación sexual a condición de que se acompañe de "valores morales", refiriéndose en realidad a sus valores; por ejemplo, el ministro presbiteriano Rubén Deras expresó que la educación laica en las escuelas promueve "la prostitución, la homosexualidad y todo tipo de destrampe sexual" 32 (p. 41); el cardenal Juan Sandoval calificó al cambio en la educación sexual en las escuelas como "pornografía barata" y afirmó que esta educación debe tener lugar en el hogar bajo el cuidado de los padres 33; el arzobispo Norberto Rivera es calificado como "férreo defensor de la institución familiar y crítico acérrimo de posturas abortistas" (p. 228) reprueba públicamente el uso del condón, sea como anticonceptivo o como prevención del SIDA 17. En otro momento, el arzobispo matiza sus opiniones, aceptó que la educación sexual debe ser laica y respetar todos los "modos de pensar", pero que debe basarse en los valores del amor; señaló que Estado e Iglesia deben tener un papel "subsidiario" en esta tarea que corresponde a los padres 24 en lo que coincide con la UNPF.

Los representantes de la Iglesia Católica han solicitado permanentemente su intervención en la elaboración de los libros y que en el diseño de programas educativos participen sus especialistas; su demanda más radical es la modificación del artículo tercero constitucional para suprimir el carácter laico de la educación pública 33 .

\section{Otros grupos}

Otras organizaciones comparten la misma posición, sus miembros militan en diversos grupos simultáneamente, declaran perseguir objetivos comunes y contar con apoyo financiero y político. La COPARMEX participa en trabajos de desarrollo social, la educación, la familia, los jóvenes, la democracia y la economía 34,35, Enlace en la Comunidad Encuentro está conformada por personas de alto nivel socioeconómico vinculadas con el Opus Dei, PROVIDA y medios de comunicación. Empresas de gran poder económico como Grupo Modelo y Bimbo apoyan a grupos conservadores como la Iglesia Católica y PROVIDA. Además existen varios grupos de filiación católica o cristiana con presencia internacional como los Legionarios de Cristo, Human Life International, Caballeros de Colón y Opus Dei cuyas dirigencias están conformadas por empresarios sobresalientes; la organización Testimonio y Esperanza apoya al PAN y está vinculada con otros grupos conservadores 17 .

\section{Análisis}

Por su papel en la socialización, en la reproducción cultural y en el desarrollo, la educación es un ámbito de interés público. La educación en salud y sexualidad se constituye en un campo de confluencia de actores sociales donde se recrean significados relacionados con los usos corporales que confrontan posiciones de los actores poniendo en juego sus propios valores.

El debate sobre educación sexual, en un sentido macro, expresa la oposición entre tradición y modernidad. Diversos actores portan como principios generadores de su discurso al dogma 
y la fe de la tradición cristiana, definiéndose así prescripciones y proscripciones sobre el cuerpo; otros actores portan los principios modernistas de la razón y la verdad, laicismo y ciencia son los ordenadores de la acción pública. Los Estados modernos crearon instituciones seculares para ejercer el poder público. La creación de ministerios o secretarías de salud y educación de carácter laico y científico expresan esa evolución.

A pesar de la naturaleza estatal de dichas instituciones, frecuentemente sus labores motivan diferendos y demandas que pueden resultar en modificaciones de las acciones previstas. En México, el uso del condón y la sexualidad se conforman en núcleos problemáticos alrededor de los que diversos actores asumen una posición particular y buscan influir en la política educativa, en ésta podemos ubicar a los actores en tres posiciones: opositores, impulsores y ejecutores; profundizamos en los opositores ya que son quienes dominan el debate público. En la tercera posición ubicamos a la SEP que no es una institución neutral, pues porta intereses específicos, pero debido a su autonomía relativa puede aparecer como conciliadora entre las otras dos posiciones, ha modificado sus acciones acorde a intereses de determinados actores. Mientras que la inclusión de temas sobre sexualidad y VIH/ SIDA en los libros de texto puede considerarse un acercamiento a la modernidad, la ausencia de otros temas y algunos cambios observados pueden representar un retroceso a la tradición.

Los libros de texto pueden considerarse medios del gobierno para transmitir ideas, socializar a las generaciones o superar rezagos sociales; pero son producto de la puesta en juego de intereses que interactúan en el Estado, lo cual los hace susceptibles de servir a intereses de ciertos grupos y no necesariamente de toda la población. En una sociedad caracterizada por la exclusión de sectores minoritarios (étnicos, sexuales y económicos), los contenidos de los libros pueden legitimar la marginación, pues la información difundida no resulta útil para estas minorías ya que no se ven reflejados en los textos.

Tras incluir contenidos sobre sexualidad, la SEP los ha modificado, hecho que coincide con la oposición de ciertos actores y sus declaraciones sobre negociaciones y acuerdos con la SEP. Algunos funcionarios han declarado que no hubo conflictos ni negociaciones con las organizaciones, pero que son "subsidiarias externas", la coexistencia de avances modernistas y rezagos nos expresan la existencia de concesiones. Las limitaciones provienen de negociaciones con quienes condicionan la educación sexual, puesto que faltan temas como la diferencia entre sexo, género y orientación sexual 3, diversidad sexual, equidad de género y uso del condón. La influencia de los opositores en este efecto, encuentra su evidencia en el debate público: la SEP declaró haber escuchado opiniones de distintos sectores y no querer conflictos, algunos opositores coincidieron en declarar que tenían una "participación" parcial, total o personal en la elaboración de los libros.

Los opositores pretenden generalizar sus valores y significados acerca de la sexualidad y el VIH/SIDA; cuestionan la eficiencia del Estado para la educación sexual y proponen que ésta tenga lugar en la familia, sin considerar que los padres no cuentan con la información adecuada y suficiente o si prefieren que sus hijos la reciban en las escuelas. Algunos dicen aceptar la educación sexual, pero anteponen condiciones como los "derechos" de los padres a educar a sus hijos y acompañarla de "valores", asumiendo que sus valores son los valores, revelando una visión radical de valores únicos e innegociables y su interés por imponerlos a toda la población. Se guían por la tradición y la fe, por estereotipos rígidos en la conducta sexual; buscan conducir y supervisar los comportamientos en un modelo limitado, censurando expresiones contrarias, el resultado es una exclusión y penalización de los individuos anormalizados y la consideración de que el VIH/ SIDA es producto de conductas inadaptadas. Así, en las políticas públicas prevalecerá la omisión u ocultamiento de sectores que no guían sus conductas por tales estereotipos y se fortalecen prejuicios otorgándose pseudoargumentos para discriminar a ciertos sectores excluyéndolos del acceso a la información; esta secuencia constituye un contexto desfavorable para prevenirse del VIH/SIDA. En términos más amplios, el proyecto político de estos sectores se opone al laicismo y a la secularización de la sociedad, sus acciones obedecen al propósito de "integrar" la vida política y social con la religión.

Nuestra investigación difiere de enfoques que abordan las decisiones estatales como un espacio cerrado y autónomo, ya que las preocupaciones del Estado no pueden ser consideradas siempre como beneficios públicos, dado que existen vínculos con actores "externos" que pueden derivar en perjuicios a distintas colectividades. Otros conceptos a tomar en cuenta en el análisis son la autonomía relativa, fuerzas externas y violencia simbólica, ya que se observó que la SEP cumplió exigencias externas bajo la apariencia de neutralidad, la violencia se verifica en la radicalidad de los conservadores que pretenden imponerse con el poder simbólico que le confieren nociones hegemónicas de la sexualidad, así como el poder económico y político de una estructura reticular que incluye actores pertenecientes a la burguesía 
y al PAN, aumentando su capacidad de interlocución con instancias gubernamentales.

\section{Conclusiones}

Los grupos opositores se caracterizan por considerar a la sexualidad un ámbito regulado por la heterosexualidad, la reproducción y la familia tradicional (oponiéndose a anticonceptivos artificiales y al condón). Sus fines son difundir esta ideología, sancionar a quienes la desacatan y condenar prácticas no reproductivas (masturbación, homosexualidad y aborto). Le asignan a la conducta sexual una naturaleza biológica, haciéndola coincidir con las diferencias anatómicas entre hombres y mujeres; en ese orden el VIH/SIDA es consecuencia de no observar las reglas y reafirma el carácter "antinatural" que les asignan a comportamientos opuestos a tal ideología.

Aunque mantienen sus intereses, los opositores muestran fases alternas de movilización y latencia que coinciden con cambios en los libros de texto y con los ciclos escolares. Son agentes sociales con poder económico y político que han establecido redes sociales entre grupos religiosos, el PAN, legisladores y el empresariado nacional. Sus acciones se orientan a influir en la política pública y su discurso incluye críticas

\section{Resumen}

Estudios y recomendaciones de organismos sanitarios han resaltado la importancia de la educación en la prevención del VIH/SIDA. En México, se han incluido temas sobre sexualidad y VIH/SIDA en los programas escolares. El hecho motiva resistencias de algunos actores sociales, este trabajo busca clarificar sus posiciones e intereses, y su influencia en los contenidos los libros de texto. Se realizó una investigación documental con fuentes hemerográficas publicadas en el periodo en que se realizó la última reforma educativa. Se hizo un análisis del discurso con el enfoque de la etnografía de la comunicación que identificó: posición de los actores, argumentos, acciones, poder económico y político y relación con otros. Los resultados muestran que los opositores se basan en una ideología de la tradición, contraria a la modernización y secularización de la vida social, sus posiciones varían del rechazo al condicionamiento. Han formado redes que les confieren poder económico y político significativos. El Estado ha cedido a algunas demandas modificando parcialmente los libros. El análisis plantea reflexionar sobre las repercusiones potenciales tales acciones en el control de la epidemia.

VIH; Síndrome de Inmunodeficiencia Adquirida; Educación en Salud; Políticas Públicas a la educación estatal que obstaculizan sus aspiraciones: laicismo, gratuidad, universalidad y obligatoriedad.

El impacto de sus acciones es variable; se documenta que con presiones se consiguió la renuncia de Bassols en 1934 por sus propuestas de educación sexual y socialista; también consiguieron sustituir algunos gráficos. Pese a la oposición, se han incluido temas sobre sexualidad y VIH/SIDA pero prevalecen limitaciones: imprecisión en la diferencia entre sexo, género y orientación sexual, planteamiento de la homosexualidad con el mismo status que la heterosexualidad y capacitación en el uso correcto del condón. Es posible que estas carencias también sean un efecto de acciones opositoras. Esto representaría un gradualismo de la política pública que no termina por incluir todas las recomendaciones de organismos sanitarios.

Las deficiencias y pendientes en la educación para prevenirse del VIH/SIDA se deben, por lo menos parcialmente, a acciones de grupos opositores. Falta ponderar la influencia de actores progresistas y su impacto en la inclusión de estos temas en los libros, es posible que sus demandas se asocien con los nuevos textos. No basta conocer las limitaciones de la información que reciben los alumnos, queda pendiente evaluar si los nuevos contenidos consiguen cambios en las actitudes y habilidades en su vida sexual.

\section{Colaboradores}

J. A. Granados-Cosme fue responsable del diseño y dirección de la investigación, conformación del marco teórico, recopilación de fuentes, análisis de los resultados y elaboración del manuscrito. K. Nasaiya participó de la conformación del marco teórico, investigación hemerográfica, recopilación de fuentes, sistematización de datos y análisis de los resultados. A. T. Brambila participó de la recopilación de fuentes y corrección de manuscrito. 


\section{Referencias}

1. Ramirez-Valles J. The protective effects of community involvement for HIV risk behavior: a conceptual framework. Health Educ Res 2002; 17:389-403.

2. Granados JA, Nasaiya K. Salud, sexualidad y SIDA en la educación pública en México. Un análisis del texto de ciencias naturales de quinto grado de primaria. Argumentos 2003; 45:39-57.

3. Nasaiya K. La política pública de prevención del VIH-SIDA del gobierno mexicano. Un análisis de los libros de texto [Tesis de Maestría]. México DF: Maestría en Medicina Social, Universidad Autónoma Metropolitana; 2002.

4. Melkote SR, Muppidi SR, Goswami D. Social and economic factors in an integrated behavioral and societal approach to communications in HIV/ AIDS. J Health Commun 2000; 5 Suppl:17-27.

5. Yoo H, Lee SH, Kwon BE, Chung S, Kim S. HIV/ AIDS knowledge, attitudes, related behaviors, and sources of information among Korean adolescents. J Sch Health 2005; 75:393-9.

6. Ministerio de Educación. Prevention at school level. Chile: "Education for prevention and non-discrimination". Child Worldw 1993; 20:70.

7. Sacadura M, Marzin P, Charbonnier F. HIV/AIDS prevention in the school setting: practices of biology teachers in France and in the Congo. Sante Publique 2005; 17:211-26.

8. Tremblay $\mathrm{CH}$, Ling DC. AIDS education, condom demand, and the sexual activity of American youth. Health Econ 2005; 14:851-67.

9. Bolos S. La constitución de actores sociales y la política. México DF: Universidad Iberoamericana/ Plaza y Valdés; 1999.

10. Martiniello M. Salir de los guetos culturales. Barcelona: Ediciones Bellaterra; 1998.

11. Touraine A. El regreso del actor. Buenos Aires: Eudeba; 1987.

12. Melucci A. ¿Qué hay de nuevo en los nuevos movimientos sociales? In: Larana E, Johnson H, Gursfiled J, compiladores. Los nuevos movimientos sociales. De la ideología a la identidad. Madrid: Centro de Investigaciones Sociológicas; 1994. p. 120-47.

13. Smelser N. Teoría del comportamiento colectivo. México DF: Fondo de Cultura Económica; 1989.

14. Petchey R, Williams J, Farnsworth B, Starkey K. A tale of two (low prevalence) cities: social movement organisations and the local policy response to HIV/AIDS. Soc Sci Med 1998; 47:1197-208.

15. Grupo de Información en Reproducción Elegida. Contraception and the right of the state in the $\mathrm{Ca}$ tholic Church. GIRE 1997; (14):2-3.
16. Bonfil C. La lucha por el alma de los niños. La Jornada 1998; 2 sep.

17. Ruíz E. La sexualidad prohibida: intolerancia, sexismo y represión. México DF: Plaza Janés; 2002.

18. Jiménez N. Olvidan libros de texto 30 años de historia. Reforma 1994; 13 sep.

19. Vargas RE. Incluir o excluir temas es una decisión de 'política educativa', dicen en la dependencia. La Jornada 1998; 31 jul.

20. Leroux J. Divan/Una probadita de educación sexual. Reforma 1998; 8 ago.

21. Duranti A. Antropología lingüística. Madrid: Cambridge University Press; 2000.

22. Hamel E. Constitución y análisis de la interacción verbal. Estudios de Lingüística Aplicada 1982; 1: 31-80.

23. Unión Nacional de Padres de Familia. Editorial. Semanario Nuevo Criterio 2001; XXIII.

24. Herrera C. Nueva andanada de la UNPF en contra de la educación laica. La Jornada 2000; 12 nov.

25. Turati M. Discrepan de Iglesia que propone educar. Reforma 1998; 18 abr.

26. Comité Nacional PROVIDA. Sexualidad humana. http://www.prodigyweb.net.mx/cprovida (accedido el 15/Oct/2002).

27. PROVIDA España. Todos fuimos embriones. http://www.ctv.es/USERS/provida (accedido el 15/Oct/2002).

28. Fundación Mexicana para la Planeación Familiar. Presentación. http://www.mexfam.org.mx (accedido el 15/Oct/2005).

29. Valasis AD. Apoyarán a seropositivos. Reforma 1995; 12 mar.

30. Lamas M. Escenas de un campo de batalla: la política sexual en México. La Jornada 1999; 7 ene.

31. Sarmiento S. Jaque mate/Saber de sexo. Reforma 1998; 31 jul.

32. Herrera C, Vargas RE. La opinión de Deras es personal, dice Olac Fuentes. La Jornada 2000; 18 ene.

33. Boffil LA, Bañuelos C. Apoyan ministros católicos reformas al artículo tercero. La Jornada 2000; 4 ago.

34. Confederación Patronal de la República Mexicana. Presentación. http://www.coparmex.org.mx (accedido el 16/Oct/2002).

35. Sección Distrito Federal, Confederación Patronal de la República Mexicana. Presentación. http://www.coparmexdf.org.mx (accedido el 16/ Oct/2002)

Recibido el 13/Dic/2005

Versión final presentada el 25/Jul/2006

Aprobado el 01/Ago/2006 